\title{
Acute Care Surgery. A Guide for General Surgeons, V. H. Gracias, M. G. McKenney, P. M. Reilly, G. C. Velmahos
}

\author{
McGraw-Hill, 2009, 464 pp, \$99.95 (amazon.com)
}

\author{
Roger Saadia
}

Published online: 9 June 2009

(C) Société Internationale de Chirurgie 2009

Acute care surgery has certainly come of age, at least in North America. Trauma and emergency adult general surgery make up the core of this new surgical specialty. The boundaries, however, may remain undefined for a long time: Must intensive care or burns management expertise be part of the package? What about basic emergency pediatric surgery? Should a trauma and acute care surgeon be encouraged or even allowed to conduct forays into well established specialties such as vascular surgery? Some of these questions will be left to licensing authorities and individual health care centers. At the moment, though, there is a pressing need for the medical publishing industry to cater to this new species of surgeons.

The book under review is organized into three parts: emergency surgery, critical care, and trauma. A single glance at the table of contents reveals the main flaw of this work: a disturbing lack of editorial guidance, despite (or perhaps because of) counting no fewer than four editors for a relatively slim volume. Why are the chapters on gastroduodenal injuries and on traumatic aortic rupture tucked into the first section rather than into the trauma section? Similarly, why did the chapter on resuscitation endpoints not find its natural place in the critical care part? There is no uniformity in the choice of chapter titles: A long-winded "Nontraumatic Emergency Surgery of the Small Intestine" is followed by a laconic "The Colon." It gets worse as one delves into the body of the text. Are you looking for the management of complicated peptic ulcers? Please report to the chapter entitled "Emergency Surgery for Stomach and Duodenum Injuries."

Taken piecemeal, chapter by chapter, the quality of the content is uneven. The section on femoral hernia is a treasure trove of historical information but remains rather skimpy on practical management guidelines. Thus, one remains in the dark about the recommended approach to such a classic general surgical emergency. In contrast, the discussion of endpoints on resuscitation is taken to extremes - to the point of being esoteric; it is doubtful whether it is appropriate in a work claiming in its preface to represent a "rapid reference" for surgeons in the "heat of battle." The chapters on acute pancreatitis and antibiotic selection are two examples, among others, of excellence; they provide a concise, balanced, practical overview of their subject matter. The choice of certain topics (for example, interface with emergency medicine or postoperative pitfalls) is deserving of special mention.

Contrary to what we are told in its foreword, this work is not a "first of its kind." A more robust and comprehensive Acute Care Surgery: Principles and Practice (L. D. Britt, D. D. Trunkey, and D. V. Feliciano, editors) has been on the market since 2007. All in all, this volume does not entirely live up to its readership's expectations. It is hoped that a subsequent edition will provide an opportunity for more logical organization of its valuable contents and greater uniformity among chapters.

R. Saadia $(\bowtie)$

Trauma and Acute Surgical Care, University of Manitoba,

Winnipeg, Canada

e-mail: rsaadia@shaw.ca 